\title{
Carbon Footprint Reduction from Energy-Saving Measure and Green Area of Suranaree University of Technology, Thailand
}

\author{
Sudjit Karuchit, Wichayanee Puttipiriyangkul, and Tanyarut Karuchit
}

\begin{abstract}
This paper presents the carbon footprint estimation of Suranaree University of Technology (SUT). It also describes the carbon footprint reduction from the implementation of the energy-saving measure and the capturing of $\mathrm{CO}_{2}$ by trees in the green area within the campus. For the academic year 2016, the total emission from sources and the total sinks of greenhouse gases (GHGs) were $13,318.64 \mathrm{tCO}_{2} \mathrm{eq}$ and 5,281.65 $\mathrm{tCO}_{2} \mathrm{eq}$, respectively, and the net carbon footprint was 8,036.99 $\mathrm{tCO}_{2} \mathrm{eq}$. Electricity usage accounted for $66 \%$ of the total emission. Other notable emitters were refrigerant leakage and waste disposal. The energy-saving measure - using energy-efficient air conditioners - can reduce the emission at considerably high costs, 33,332 baht/ $\mathrm{tCO}_{2}$ eq. These air conditioners also use a higher GWP-value refrigerant, type $\mathrm{R}-410 \mathrm{a}$. The green area played a very important role as the only sink of GHGs in the university. It captured approximately $\mathbf{4 0 \%}$ of the total emission value. From the 4-year projection scenario, the net carbon footprint of the university has a downward trend, decreasing at an average rate of $1,005.46 \mathrm{tCO}_{2} \mathrm{eq}$ per year.
\end{abstract}

Index Terms - Carbon footprint, energy-saving, green area, greenhouse gases.

\section{INTRODUCTION}

Climate change caused by anthropogenic emission of greenhouse gases (GHGs) is undeniably an imminent threat to the health and welfare of the world's population. To reduce the country's GHGs emissions, Thailand Greenhouse Gas Management Organization (TGO) was established to be the center for collaboration among the 3 stakeholders: governmental agencies, private sector, and international organizations. TGO's responsibility includes promoting the estimation of GHGs emissions in the country and providing management guidelines to effectively reduce GHGs emissions. One of the guidelines, Guidelines for Estimating Carbon Footprint of Organizations, can be adopted by industrial organizations, local administrative offices, or academic institutes [1]. Consequently, the first carbon footprint estimation of Suranaree University of Technology (SUT) was carried out in 2016 using this guideline [2]. The results were among other universities which have reported their studies in the literature [3]-[8].

The first autonomous university in Thailand, SUT is in

Manuscript received August 4, 2019; revised January 19, 2020. This work was supported by Suranaree University of Technology through the SUT's Environment Fund.

The authors are with Suranaree University of Technology, Nakhon Ratchasima, Thailand (e-mail: sudjit@sut.ac.th, view74713@gmail.com, tanyarut.g@gmail.com).
Nakhon Ratchasima province in the north-eastern part of the country. It has approximately 20,000 students, lecturers, and staffs combined, and the campus area of 6,911 rais. Early results of the study of GHGs emission of SUT was presented in a related paper [9]. The goals of this paper are to 1) presents the carbon footprint estimation from the sources and sinks of GHGs in Suranaree University of Technology, Thailand; and 2) analyze the carbon footprint reduction as a result of the energy-saving measure implement by the university and the carbon dioxide captured by the green area within the university.

\section{Methodology}

\section{A. Defining Boundaries}

The methodology in this study followed the Guidelines for Estimating Carbon Footprint of Organizations by TGO. The first step was the identification of the organization boundary - the sources of GHGs emission and storage to be included in the analysis. The organization boundary for this study consisted of the internal units under the operational control of the university: the university council, the office of the president, institutions, centers, enterprise units, and other units. There were also units which were defined based on area: residential areas, green area, water supply system, wastewater treatment system, and waste disposal system.

The other boundary which had to be defined was the operational boundary. It involves defining sources and sinks of the GHGs related to the university operation to be included in the analysis. The operational boundary for GHGs sources in this study consisted of 3 groups, or "Scopes". Scope 1, direct emission, consisted of power generation, LPG usage, vehicle fuel combustion, refrigerant, fire extinguisher, fertilizer and detergent usage, and manure from animal farms. Scope 2 was the indirect emission from electricity. Scope 3, indirect emission from other sources, consisted of traveling by personnel, water supply, use of office and toilet papers, waste disposal, and tenant usage of fuel, electricity, and water. The operational boundary for GHGs sinks in this study consisted of only 1 group - the capture of $\mathrm{CO}_{2}$ by trees in the green area of the university.

\section{B. Data Collection}

Pertinent information of the university's activities in the academic year 2016 was gathered for each activity defined in the operational boundary. For the sources of GHGs, primary data collected included surveying, personnel interviews, questionnaires, and data extraction from operational records. 
Secondary data collected included electricity bills, equipment and supplies records, receipts, disbursement records, and operational records.

For the sink of GHGs, the trees in the green area were sampled for their numbers, types, heights, and diameters. Within the 6,911 rais ( 1 rai $=1,600$ square meters $)$ of the university area, approximately 1,793 rais $(26 \%)$ were the green area defined in this study. It was divided into 6 sub-areas, as shown in Fig. 1. For each sub-area, two $20 \times 20$ square meters sampling areas were randomly located. Within each sampling area, two $4 \times 4$ square meters data collection areas were then randomly located. Trees in each of these areas that were higher than 1.30 meters and had diameters greater than 4.5 centimeters were measured for their heights and diameters at breast height (1.30 meters).

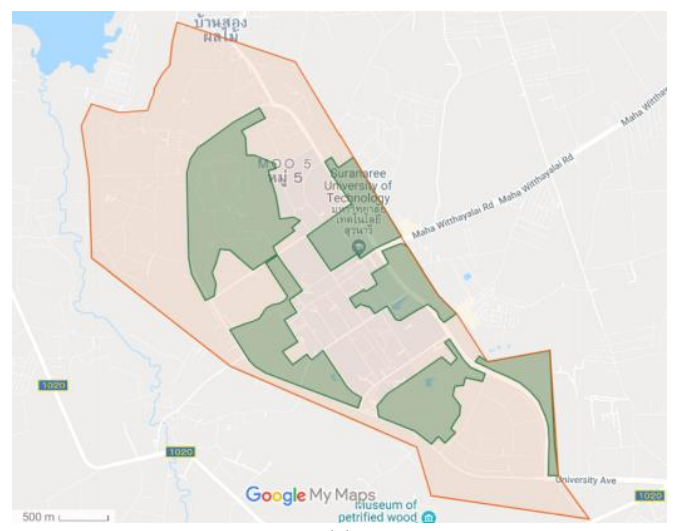

(a)

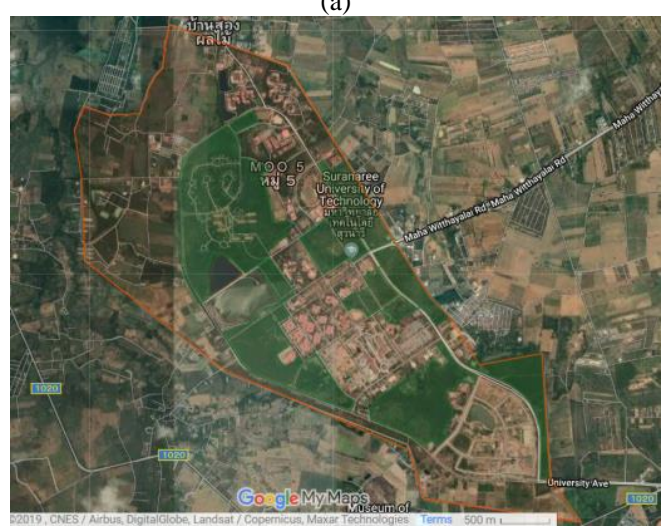

(b)

Fig. 1. The green area in the university, divided into 6 sub-areas: (a) basic area map and (b) satellite image map.

\section{Calculation of GHGs Emission from Sources}

The amount of GHGs emission from the university sources was calculated from the activity data and corresponding emission factors using (1) and (2):

$$
\begin{gathered}
E_{A}=A \times E F \\
E_{T}=(D / F) \times E F
\end{gathered}
$$

where $E_{A}$ and $E_{T}$ are the GHGs emission from activity and trip, respectively; $A$ is the activity data, $D$ is the distance traveled, $F$ is the fuel consumption rate, and $E F$ is the emission factor. The unit of GHGs emission is ton $\mathrm{CO}_{2}$ equivalent $\left(\mathrm{tCO}_{2} \mathrm{eq}\right)$. The GHGs emission factor used in the calculation of each activity is based on recommendations by TGO [1].

\section{Calculation of GHGs Reduction from Sinks}

Calculation of GHGs reduction from sinks involved the estimation of carbon dioxide captured by trees in the university's green area. First, the carbon storage in trees can be calculated from the total above-ground biomass $\left(W_{T}\right)$ using the allometric equations [10]. $W_{T}$ is the sum of stem wood biomass $\left(W_{S}\right)$, branch biomass $\left(W_{B}\right)$ and leaf biomass $\left(W_{L}\right)$. These biomass values are related to the tree heights $(H)$ and diameters at breath height $(\mathrm{DBH})$. For trees of general type, the calculation of $W_{S}, W_{B}, W_{L}$, and $W_{T}$ of each tree follows (3) to (6) [11].

$$
\begin{gathered}
W_{S}=0.0396\left(D^{2} H\right)^{0.933} \\
W_{B}=0.00349\left(D^{2} H\right)^{1.030} \\
W_{L}=\left(28 /\left(W_{S}+W_{B}+0.025\right)\right)^{-1} \\
W_{T}=W_{S}+W_{B}+W_{L}
\end{gathered}
$$

The units of $D$ and $H$ used in the equations are centimeters and meters, respectively. The units of biomass values are kilograms. The amount of carbon in the trees can then be calculated by multiplying $W_{T}$ with 0.47 , the conversion factor representing the proportion of carbon in the total biomass [10]. Finally, the carbon dioxide storage can be computed from the carbon storage multiplied by the molecular weight of carbon dioxide per carbon mass (44/12) to obtain the unit to the mass of carbon dioxide equivalent.

The $\mathrm{CO}_{2}$ captured annually by trees, or the mean annual increment (MAI), can be estimated from the difference of carbon dioxide storage between the base year $\left(C_{0}\right)$ and the $\mathrm{n}^{\text {th }}$ year $\left(C_{n}\right)$, as shown in (7).

$$
M A I=\left(C_{n}-C_{0}\right) / n
$$

\section{RESULTS AND DISCUSSION}

\section{A. Carbon Footprint Estimation}

Table I shows the calculation results of $\mathrm{CO}_{2}$ captured by trees in the green area of the university. The above-ground biomass, carbon storage, and $\mathrm{CO}_{2}$ storage in the academic year 2016 were $15.5 \mathrm{tC} / \mathrm{rai}, 7.14 \mathrm{tC} / \mathrm{rai}$, and $25.03 \mathrm{tCO}_{2} / \mathrm{rai}$, respectively. The total $\mathrm{CO}_{2}$ storage in the green area was $44,882 \mathrm{tCO}_{2}$. The $\mathrm{CO}_{2}$ captured in the year 2016, 5,282 $\mathrm{tCO}_{2}$, was calculated from the MAI equation, using the year 2015 as the base year and $n=1$.

Table II shows the summary results of the GHGs sources and sinks calculation. For the GHGs sources, the direct emission (Scope 1), electricity (Scope 2), and indirect emission (Scope 3) were equal to 2,807.92, 8,808.63 and $1,634.22 \mathrm{tCO}_{2} \mathrm{eq}$, or $21 \%, 66 \%$ and $12 \%$, respectively. It was unmistakable that Scope 2 - electricity usage - dominated the overall emission. Furthermore, it should be noted that refrigerant leakage and waste disposal were the second and third largest contributors, respectively. Both were in Scope 1. The total emission from GHGs sources was $13,318.64$ $\mathrm{tCO}_{2}$ eq. For the GHGs sink, on the other hand, the total $\mathrm{CO}_{2}$ captured in the year 2016 by the green area was equal to 
$5,281.65 \mathrm{tCO}_{2}$ eq. The net value of Suranaree University of Technology's carbon footprint was calculated from the total
GHGs emission (source) minus the total GHGs reduction (sink), which was equal to $8,036.99 \mathrm{tCO}_{2} \mathrm{eq}$.

TABLE I: $\mathrm{CO}_{2}$ STORAGE AND CAPTURE BY THE GREEN AREA IN SUT

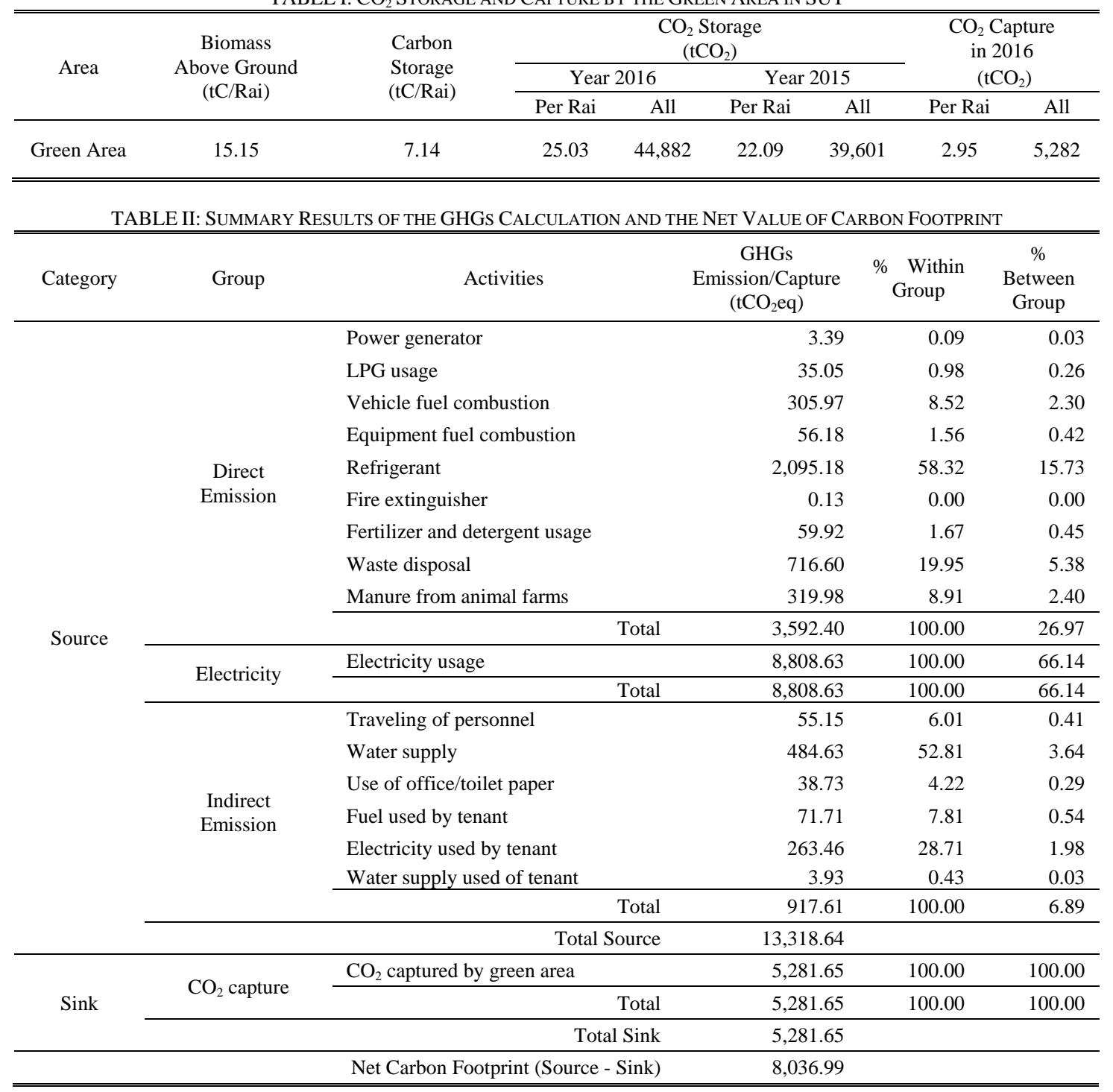

\section{B. Carbon Footprint Reduction Analysis}

Analysis of carbon footprint reduction focused on the major source and sink of GHGs of the university. The electricity usage was the most important source, accounting for over $66 \%$ of the university's carbon footprint. On the other hand, the green area had a very important role as the only sink of GHGs in the university. It captured 5,281.65 $\mathrm{tCO}_{2} \mathrm{eq}$, which was approximately $40 \%$ of the total source emission value. This section explores the university's carbon footprint reduction scenarios that involve an energy-saving measure and the annual $\mathrm{CO}_{2}$ capture by green area.

As an energy-saving measure, the university's Division of Building and Ground (DBG) have plans for replacing the existing, old air conditioners in selected buildings every year. The new air conditioners are the ones with a higher energy efficiency ratio (EER). They also have the variable refrigerant flow (VRF) systems, which can adjust the amount of refrigerant flow according to the working load and the number of units served. Both features make the new air conditioners more energy-efficient, which leads to energy saving and thus the GHGs emission reduction.
Fig. 2 shows the analysis of the measure with regards to the GHGs reduction, based on the DBG plan during the academic year $2017-2020$. The cumulative cost is estimated to be 20.76 million baht (Fig. 2 (a)). The amount of GHGs reduced via this measure will be $622.07 \mathrm{tCO}_{2}$ eq in 2020 . The annual costs of GHGs reduction vary slightly, with the average value equals to 33,332 baht $/ \mathrm{tCO}_{2}$ eq (Fig. 2 (b)).

The new air conditioners, however, have an undesirable aspect regarding their refrigerant - type R-410a. When compared with the refrigerant used in the existing air conditioners, type R-22, the new chemical has a higher Global Warming Potential (GWP) value. As a result, the annual emission from refrigerant leakage increased, as shown in Fig. 3 (a). The additional GHGs emission from refrigerant change will be $34.29 \mathrm{tCO}_{2}$ eq in 2020 (Fig. 3 (b)).

As for the GHGs reduction through $\mathrm{CO}_{2}$ storage by trees in the green area, the amount stored in 2015 and 2016 were $39,601 \mathrm{tCO}_{2}$ and 44,882 $\mathrm{tCO}_{2}$, respectively. The increase of $\mathrm{CO}_{2}$ storage from 2015 was considered the $\mathrm{CO}_{2}$ captured in 2016. That amount was $5,282 \mathrm{tCO}_{2}$, which was equal to $13.34 \%$ of the $\mathrm{CO}_{2}$ storage in 2015 . 

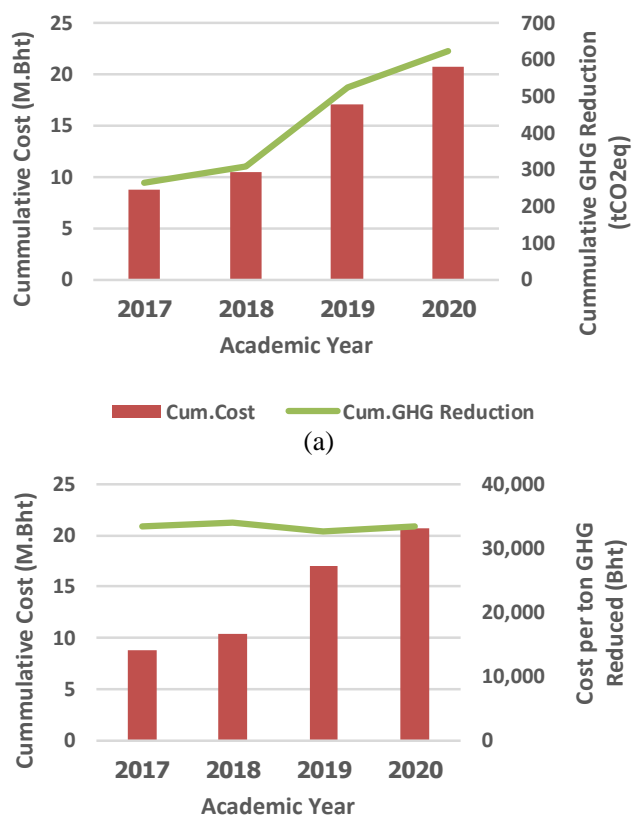

Cum.Cost $\quad$ Cost per ton GHG Reduced

(b)

Fig. 2. Analysis of energy-saving measure by changing air conditioners: (a) cumulative cost and cumulative GHG reduction and (b) cumulative cost and cost per ton GHG reduced.

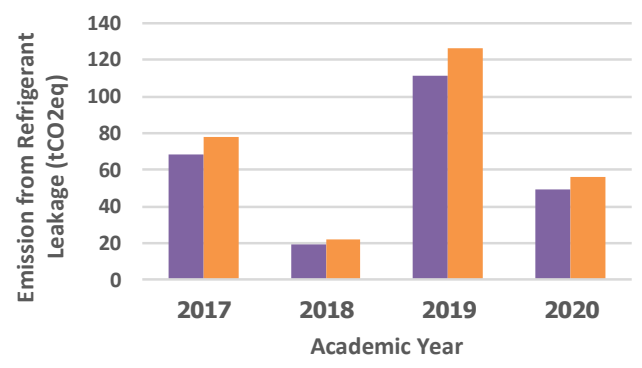

R-22 R-410

(a)

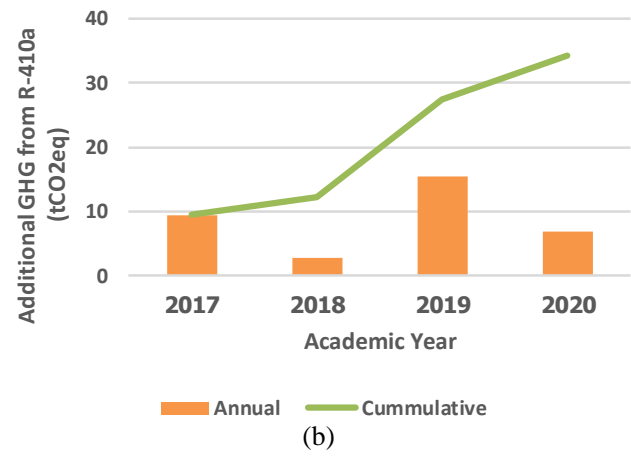

Fig. 3. Emission from refrigerant leakage: (a) comparing R-22 and R-410a usage and (b) additional GHGs emission from the use of R-410a.

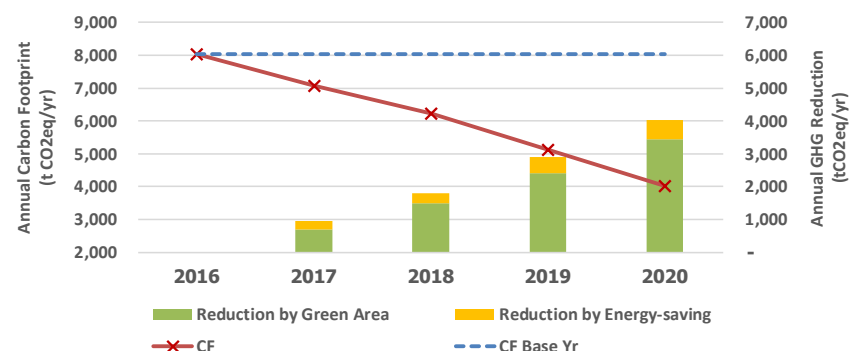

Fig. 4. Projection of carbon footprint of Suranaree University of Technology during the academic year $2017-2020$.

Fig. 4 shows the projection of the carbon footprint of
Suranaree University of Technology during the academic year 2017 - 2020. The assumptions were that all emissions were constant, and the only changes were the annual reduction of GHGs from the energy-saving measure and the green area $\mathrm{CO}_{2}$ capture. The annual reduction by green area was calculated based on the assumption that the $\mathrm{CO}_{2}$ captured each year equals to $13.34 \%$ of the $\mathrm{CO}_{2}$ storage of the earlier year. This assumption means the existing green area is preserved and the trees are allowed to grow naturally without significant biomass loss from branch cutting or trimming. From the projection, the annual carbon footprint of the university has a downward trend, decreases from $8,036.99 \mathrm{tCO}_{2} \mathrm{eq}$ in 2016 (base year) to $4,015.16 \mathrm{tCO}_{2} \mathrm{eq}$ in 2020. The average annual reduction rate over the 4 years is $1,005.46 \mathrm{tCO}_{2} \mathrm{eq}$ per year. It is apparent that the more significant reduction comes from the green area. The energy-saving measure accounted for only $15 \%-27 \%$ of the total reduction annually.

\section{CONCLUSION}

For the academic year 2016, the estimated university's carbon footprint was $8,036.99 \mathrm{tCO}_{2}$ eq. The most significant emission came from electricity usage, $66 \%$. The green area captured nearly $40 \%$ of the total emission. The energy-saving measure of installing new, more energy-efficient air conditioners can reduce the GHGs emission but has substantial costs and an undesirable usage of higher GWP-value refrigerant. The capture of $\mathrm{CO}_{2}$ by the green area contributed more significantly. From the 4 -year projection scenario, the average GHGs reduction rate is $1,005.46$ $\mathrm{tCO}_{2}$ eq per year. The findings and the approach of this work are valuable parts of the foundation for carbon footprint analysis and reduction of the university.

\section{CONFLICT OF INTEREST}

The authors declare no conflict of interest.

\section{AUTHOR CONTRIBUTIONS}

W. Puttipiriyangkul and S. Karuchit conducted the research and analyzed the data; S. Karuchit and T. Karuchit analyzed the carbon footprint reduction options and wrote the paper. All authors had approved the final version.

\section{REFERENCES}

[1] Guidelines for Estimating Carbon Footprint of Organizations, 3rd ed Thailand Greenhouse Gas Management Organization (TGO), Bangkok, Thailand, 2016.

[2] W. Puttipiriyangkul, "Carbon footprint evaluation and greenhouse gases emission reduction of Suranaree University of Technology,' M.Eng. thesis, School of Envi. Eng., Suranaree Univ. of Tech., Nakhon Ratchasima, Thailand, 2019.

[3] D. Tilley, R. Serour, M. Ruth, K. Ross, C. Horin, and L. Ness, Carbon Footprint of the University of Maryland, College Park: An Inventory of Greenhouse Gas Emissions, 2002-2008, The Center for Integrative Environmental Research (CIER), 2009, pp. 32-34.

[4] H. N. Larsen, J. Petersen, C. Solli, and E. G. Hertwich, "Investigating the carbon footprint of a university - The case of NTNU," Journal of Cleaner Production, vol. 48, pp. 39-47, June 2013.

[5] L. Ozawa-Meida, P. Brockway, K. Letten, J. Davies, and P. Fleming, "Measuring carbon performance in a UK University trough a consumption-based carbon footprint: De Montfort University case 
study," Journal of Cleaner Production, vol. 56, pp. 185-198, October 2013.

[6] S. M. Abolarin, A. O. Gbadegesin, M. B. Shitta, A. Yussuff, C. A. Eguma, L. Ehwerhemuepha, and O. Adegbenro, "A collective approach to reducing carbon dioxide emission: A case study of four University of Lagos Halls of residence," Energy and Buildings, vol. 61, pp. 318-322, June 2013.

[7] R. J. Clabeaux, "Building a carbon footprint of Clemson University main campus," M.S. thesis, Dept. of Envi. Eng. and Earth Sci., Clemson Univ., SC, 2017.

[8] H. D. Bush, "Capturing, mapping, and analyzing Clemson University's academic building utility consumption," M.S. thesis, Dept. of Envi. Eng. and Earth Sci., Clemson Univ., SC, 2018.

[9] W. Puttipiriyangkul and S. Karuchit, "Study of greenhouse gases emission and storage of Suranaree University of Technology, Thailand," in Proc. the $10^{\text {th }}$ International Conference on Sciences, Technology and Innovation for Sustainable Well-Being (STISWB 2018), 2018.

[10] IPCC Guidelines for National Greenhouse Gas Inventories, Intergovernmental Panel on Climate Change (IPCC), Japan, 2006

[11] H. Ogawa, K. Yoda, and T. Kira, "A preliminary survey on the vegetation of Thailand," Nature and Life in SE Asia, pp. 121-157, 1965.

Copyright $(\odot) 2020$ by the authors. This is an open access article distributed under the Creative Commons Attribution License which permits unrestricted use, distribution, and reproduction in any medium, provided the original work is properly cited (CC BY 4.0).

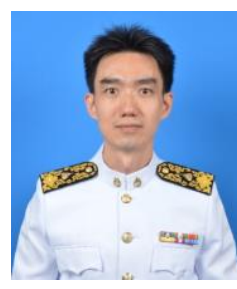

years.
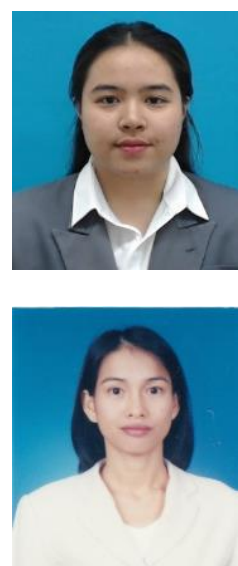

part-time lecturer.
Sudjit Karuchit received a bachelor's degree from Chulalongkorn University in 1992, a master's degree from Asian Institute of Technology in 1995, and a Ph.D. degree from Illinois Institute of Technology, USA., in 2001 - all in the field of environmental engineering. He has been working as a faculty member of the School of Environmental Engineering, Suranaree University of Technology for more than 18

Wichayanee Puttipiriyangkul received her bachelor of science's degree in environmental health from Suranaree University of Technology in 2015. She then pursued her master of engineering's degree in industrial systems and environmental engineering at the same institute. Before graduating in 2019, she has been working as a teaching assistant and also participating in several environmental projects.

Tanyarut Karuchit graduated from Khon Kaen University in 1992 with a bachelor's degree in environmental engineering. She received her master's degree in the same field from Asian Institute of Technology in 1995. She has been working as an environmental engineer in various environmental impact assessment (EIA) projects. She also teaches courses at Suranaree University of Technology as a 